странством // Уральский исторический вестник. 2013. № 3. С. 59-68.

3. Загидуллин И.К. О религиозно-культурной автономии татар в округе оренбургского магометанского духовного собрания // Ислам в современном мире: внутригосударственный и международно-политический аспекты. 2015. Т.11. № 3. С. 61-70.

4. Любичанковский С.В. Кризис губернского управления регионами в позднеимперской России // Федерализм. 2007. № 1. С. 127-140.

5. ПСЗ-1. Т.ХХ. № 14392.

6. ПСЗ-1. Т.XXI. № 15774.

7. РГАДА. Ф.16. Оп.1. Д.636.

8. Лысенко Л.М. Губернаторы и генерал-губернаторы Российской империи (XVIII - начало XX века). М.: Изд-во МПГУ, 2001. 353 с.

9. ПСЗ-1. Т.XXI. № 15141

10. ПС3-1. Т.XXII. № 16710

11. ПСЗ-1. Т.XXIV. № 17634

12. РГИА. Ф.383. Оп.9. Д.7674. Л.73.

13. ПСЗ-2. Т.ХІІ. № 10303

14. Загидуллин И.К. Урало-Поволжский регион как «внутренняя периферия» империи (управленческий контекст) // Местное управление в пореформенной России: механизмы власти и их эффективность. Сводные материалы заочной дискуссии. ЕкатеринбургИжевск: УИИЯЛ УрО РАН, 2010. С. 450-452.

15. Любичанковский С.В. «Внутренняя периферия» Российской империи: средне-волжский вариант //
Вестник Ленинградского государственного университета им. А.С. Пушкина. 2013. Т.4. № 2. С. 165-169.

16. ПСЗ-2. T.XL. № 42058

17. ПСЗ-2. Т.ХІХ. № 17998

18. СЗРИ. Т.2. Общее Учреждение Губернское (изд. 1892 г.). Ст.437-438, 467-471.

19. РГИА. Ф.1284. Оп.185. 1910. Д.29. Л.93об.

20. ГАОО. Ф.10. Оп.1. Д.175. Л.1-2.

21. Усиление губернаторской власти. Проект фон Плеве. С предисловием П.Струве и с приложением дела орловского губернатора Неклюдова. Париж: «Освобождение», 1904. $112 \mathrm{c}$.

22. Крафт И.И. Сборник узаконений о киргизах степных областей. Оренбург: Губернская типография, $1898.314 \mathrm{c}$.

23. Зиманов С.3. Политический строй Казахстана конца XVIII и первой половины XIX века. Алма-Ата: Политиздат, 1958. 428 с.

24. ПС3-1. Т.XXXVIII. № 29126.

25. ПС3-3. T.II. № 886.

26. ПС3-3. Т.XVIII. № 14908.

27. ПСЗ-1. Т.ХХУ. № 18477.

28. Годовова Е.В. Оренбургское казачье войско в XIX веке // Современная наука: актуальные проблемы теории и практики. Серия Гуманитарные науки. 2013. № 3-4. С. 16-21.

29. ПС3-2. T.XL. № 42058

\title{
ADMINISTRATIVE AND MANAGEMENT SYSTEMS IN TERRITORIES OF TATARS LIVING AT THE END OF XVIII - THE BEGINNING OF THE XX CENTURIES
} (C) 2016

\author{
S.V. Lyubichankovskiy, doctor of historal sciences, head of the Chair of History of Russia \\ Orenburg State Pedagogical University, Orenburg (Russia)
}

Abstract. This article deals with the administrative and management systems which were used in the territory where Tatars lived (Ural-Volga region) in the Russian Empire. It is established that the living of the Tatar people wasn't considered as the main feature of the region. Thus, until 1917 there was no plan to set up a separate administrative unit covering the area of the prevailing Tatar population (unlike, for example, the Bashkir and Kazakhs). The then administrative system reflected the imperial character of the Russian state. It manifested itself in the formation of a vertical power structure supported by the local elite and taking into account local management traditions, but controlling all key institutes and positions. The hypothesis is proved that evolution of the Russian government in the territory of the Ural-Volga region was based on the process of gradually pulling up suburban territories to the standards of local management in central Russia. These standards didn't consider national traditions of management, were based on the unified principles of rationalization and bureaucratization of management with the priority of state interests in administrative practice.

Keywords: administrative and management system, Tatars, Russian empire, Ural-Volga region, empire, local elite, internal periphery, local management, national traditions.

УДК 94(47):327

\section{ДИПЛОМАТИЧЕСКАЯ ДЕЯТЕЛЬНОСТЬ Н.В. ЧАРЫКОВА В МЕМУ АРАХ СОВРЕМЕННИКОВ}

(C) 2016

\section{О.А. Чернов, кандидат исторических наук, доцент кафедры отечественной истории и археологии} Самарский государственный социально-педагогический университет, Самара (Россия)

\footnotetext{
Аннотащия. Актуальность данной статьи состоит в том, что Н.В. Чарыков был крупным российским дипломатом, оставившим заметный след во внешней политике России. Его деятельность отражена во многих официальных документах. Однако они не в полной мере представляют его взаимодействие с другими государственными служащими Российской империи, а, следовательно, и не отражают в полной мере атмосферу в которой действовал дипломат. Вместе с тем, мемуарные источники, изначально содержащие субъективный взгляд, не способны дать объективной характеристики его деятельности. При этом комплекс мемуаров самого дипломата в данной статье не рассматривается, поскольку преследуется цель изучения мнения его современников.
} 
Таким образом, рассмотренные мемуары можно классифицировать на два основных типа - дневники и воспоминания. Причем дневники можно разделить так же на два вида - деловые и личные. Последний вид существенно проигрывает первому в информативности. Личный дневник имеет преимущество перед деловым с точки зрения эмоциональной окрашенности и в определенной степени воспроизводит отношения упоминаемых индивидов. Отмечено, что важное влияние имеет род деятельности мемуариста. Мемуары дипломатов содержат более взвешенную оценку деятельности дипломата. Авторы, не являвшиеся дипломатами, обнаруживают свою некомпетентность. Рассмотренные мемуары содержат различные, порой противоположные оценки деятельности дипломата, что в очередной раз позволяет убедиться в их субъективности. Вместе с тем они помогают точнее формировать понимание мотивов его деятельности и отношения к нему окружающих.

Ключевые слова: Н.В. Чарыков, В.Н. Ламздорф, С.Д. Сазонов, С.Ю. Витте, В.Н. Коковцов, Г.П. Федоров, С.В. Чиркин, Р.Р. Розен, А.И. Нелидов, А.А. Богданович, П.А. Шувалов, Н.К. Гирс, внешняя политика России, мемуары

Н.В. Чарыков - крупный российской дипломат, оставивший заметный след во внешней политике России последней трети XIX - начала XX вв. [1]. Его деятельность отражена во многих официальных документах. Однако они не в полной мере представляют взаимодействие Н.В. Чарыкова с другими государственными служащими Российской империи, а, следовательно, и не отражают в полной мере атмосферу в которой действовал дипломат. Вместе с тем, мемуарные источники, изначально содержащие субъективный взгляд не способны дать объективной характеристики его деятельности. При этом комплекс мемуаров самого Н.В. Чарыкова в данной статье не рассматривается, поскольку преследуется цель изучения мнения его современников [2].

Практически все этапы дипломатической деятельности Н.В. Чарыкова получили оценку современников.

Так период службы Н.В. Чарыкова в Средней Азии нашел отражение в воспоминаниях. Г.П. Федоров один из сотрудников миссии вспоминал: «Первым агентом был назначен камер-юнкер Чарыков, очень неглупый, прекрасно образованный и богатый человек. Обладая солидным дипломатическим тактом, он сразу установил с эмиром и его министрами наилучшие отношения, и, благодаря положенной им закваске, прекрасные отношения нашего политического агентства к правительству эмира никогда впоследствии не нарушались» [3, с. 451].

Кроме того, он добавил, что Н.В. Чарыков «Молодой тогда ещё дипломат, первым назначенный на должность нашего дипломатического представителя в Бухаре... Был строго выдержанный, всегда чрезвычайно корректный и тактичный человек. Враг чёрствой канцелярщины, прекрасно образованный, благовоспитанный и с большим состоянием, он сразу установил прекрасные отношения с его главными сотрудниками.

Настойчивый в своих требованиях, Чарыков умел добиться всегда их осуществления, не оскорбляя самолюбия бухарских чиновников и оставался с ними в самых лучших отношениях. Это был, действительно, дипломат в лучшем значении этого слова Дальнейшая его карьера в Европе лишь подтверждает это о нем мнение» [3, с. 890-891].

Другой дипломат - С.В. Чиркин вспоминал: «Чарыков слыл старым туркестанцем так как был первым дипломатическим чиновником при туркестанском генерал-губернаторе и первым политическим агентом в Бухаре, то есть на постах, которыми закончилась революцией моя карьера» [4, с. 195].

Следующий период отражен в мемуарах Р.P. Розена. Так, он утверждает, что Н.В. Чарыков совместно с послом в Турции А.И. Нелидовым вынашивали план объединения балканских стран в единый союзнический блок [5, p. 130].

Имеются противоречивые данные относительно службы Н.В. Чарыкова в Германии. Так, А.А. Богданович пишет в дневнике: «Сегодня слышала интересный рассказ Шелькинга. Когда Чарыков был в Берлине и пришел однажды делать доклад гр. Шувалову, который в это время уже отчасти выпил, то Шувалов во время доклада перебил Чарыкова и сказал: «Коля Чарыков, перестань комарам ставить клистиры». - «Вот в этих словах весь Чарыков», - сказал Шелькинг» [6, с. 482].

Однако дневник В.Н. Ламздорфа свидетельствует о высокой степени доверия к Н.В. Чарыкову со стороны руководства.

Так, в первые дни января 1895 г. Н.В. Чарыков решал сложный вопрос о двойной замене российского посла в Германии [7, с. 108-116]. Более того, упомянутый в дневнике А.А. Богданович посол П.А. Шувалов сообщал Н.К. Гирсу, что ввёл в курс всех, в том числе и секретных, нюансов в русско-германских отношениях Н.В. Чарыкова, «который как поверенный в делах должен быть полностью в курсе всего, что творится вокруг нас» [7, с. 116]. Дневник В.Н. Ламздорфа свидетельствует, что в августе 1895 г. 18 (30) августа 1895 г. Н.В. Чарыков принимал активное участие в согласовании позиций России и Германии по проблеме японокитайских отношений [7, с. 242].

Имеются мемуарные свидетельства и о периоде работы в Ватикане.

Видный российский советский дипломат Ю.Я. Соловьёв, в то время ещё начинающий службу, общался с Н.В. Чарыковым в Риме и отметил его как «крупного дипломата» $[8$, с. 6]. По его мнению, он «как государственный деятель не стоял высоко, но был вполне порядочным и разумным человеком» [8, с. 211]. Ю.Я. Соловьёв указывает, что секретарём российской миссии, возглавляемой Н.В. Чарыковым, был С.Д. Сазонов будущий министр иностранных дел и Чарыков уже тогда «как бы пасовал перед ним» [8, с. 111].

Из второстепенных моментов следует отметить дневниковую запись М.Ф. Шиллинга, который в своём дневнике отметил скупо: «Не стану описывать завтраков и обедов у Нелидовых, Чарыковых» [9, с. 389].

Деятельность Н.В. Чарыкова как товарища министра иностранных дел нашла место в трудах ряда мемуаристов.

Так, М.А. Таубе сообщает весьма важное обстоятельство, что «юридические дела были переданы Извольским в верховное распоряжение товарищу министра» [10, с. 106].

Достаточно подробная информация о деятельности Н.В. Чарыкова в данный период содержится в воспоминаниях В.Н. Коковцова. Из них следует, что, когда 
А.П. Извольский и Н.В. Чарыков думали, что делают всё тайно, они ошибались. Так, Столыпин показал Коковцову вырезку из венских газет, переданную ему Главным управлением по делам печати, сообщавшую в виде слуха, что во время пребывания в имении австрийского посла в России Берхтольда министров иностранных дел - Австро-Венгрии Эренталя и России А.П. Извольского было достигнуто принципиальное соглашение относительно аннексии Австро-Венгрией Боснии и Герцоговины, переданных по Берлинскому трактату 1878 г. во временное управление монархии [11, с. 332-336].

Между тем, по мнению В.Н. Коковцова, окончательная судьба этих провинций Берлинским трактатом 1878 г. не была решена, и «для всех было очевидно, что судьба их не могла быть решена иначе, как в таком же порядке общеевропейского соглашения, каким представлялся и сам Берлинский трактат» [11, с. 332-336].

П.А. Столыпин сообщил В.Н. Коковцову, что он спрашивал Н.В. Чарыкова, что ему известно по этому поводу, но тот сказал, что Извольский не оставил ему никаких указаний перед своим отъездом, ничего не писал с дороги и никаких сообщений о своем пребывании в Бухлау ему не присылал, но, несомненно, был в этом имении и провел там довольно долгое время.

Н.В. Чарыков заметил, что в МИДе никакой подготовки по этому вопросу перед отъездом Извольского из Петербурга не было и императору по данному вопросу никаких записок делаемо не было, как не было представляемо Государю никаких записок [11, с. 332-336].

При этом П.А. Столыпин обратил внимание на вскользь упомянутый Н.В. Чарыковым факт, что вероятно газетная заметка повторяет какой-либо слух из прежних времён, когда Извольский, действительно, неоднократно разговаривал с Эренталем, тогда еще послом в России, по поводу возможной комбинации. Суть комбинации состояла в том, чтобы получить принципиальное согласие Австро-Венгрии на открытие черноморских проливов для России взамен на её согласие на аннексию Боснии и Герцеговины, тем самым нейтрализовав и австрийского союзника - Германию [11, с. 332-336].

В.Н. Коковцов отмечает, что сам Н.В. Чарыков впоследствии пришел к нему «как к своему лицейскому товарищу» и сказал, что сложившееся положение «чрезвычайно щекотливое», так как он не знает в точности, где находится сейчас Извольский, несомненно, выехавший уже из Бухлау. При этом он думает, что слух этот совершенно справедлив, и «неприятность его не столько прискорбна для нас по существу, сколько по совершенной ненадобности именно нам облегчать положение Австрии, несомненно давно решившейся аннексировать эти провинции, но не нам же, естественным покровителям славянских народностей, протягивать руку Габсбургскому Дому в достижении его мечтаний, которые, во всяком случае, будут восприняты болезненно славянским миром, и на нашу голову посыплются обвинения в какой-то закулисной интриге, совершенно ненужной для нас».

При этом Н.В. Чарыков заявил, что твердо убежден и в том, что этим шагом Россия нисколько не приближается к разрешению вопроса о проливах. По его мнению, Извольский постоянно возвращался к его комбинации и верил в то, что он проведет Эренталя и сделает великое русское дело, не поступаясь никакими нашими интересами, так как никто не верит в то, что когда-либо
Берлинский договор будет пересмотрен, и вопрос о Боснии и Герцоговине получит иное решение, нежели то, временное, которое было принято в 1878 году».

Н.В. Чарыков, по словам В.Н. Коковцова, отметил, что А.С. Суворин «рвет и мечет по поводу самовольства Австрии» и не хочет допускать и мысли о том, что мы сыграли тут такую странную роль без всякой в том надобности, а когда станет ясно, что Извольский попался на эренталевскую удочку, то он не сомневался, что положение министра будет весьма незавидное и в глазах всей Европы [11, с. 332-336].

В.Н. Коковцов указывает, что Н.В. Чарыков якобы, сказал ему вскользь, что он считает свое положение невыносимым и очень надеется на то, что ему скоро удастся покинуть свой незавидный пост, так как А.П. Извольский докладывал уже Николаю II о его просьбе назначить его на место посла в Константинополь, вакансия которого должна очень скоро освободиться.

По мнению В.Н. Коковцова, А.П. Извольский очень умело решил две проблемы: исполнил желание своего однокурсника по Лицею Н.В. Чарыкова и угодил П.А. Столыпину, предложив его родственнику С.Д. Сазонову, давно желавшему покинуть пост посланника при папском престоле, должность товарища министра, которую тот «принял с большим восторгом» [11, c. 332-336].

При этом уже упомянутый выше Ю.Я. Соловьёв вспоминал, что А.П. Извольский будто бы упрекнул Чарыкова в том, что он сам добился этого назначения у П.А. Столыпина [8, с. 216].

Без каких-либо комментариев констатирует назначение Н.В. Чарыкова на должность посла в Турции С.Д. Сазонов [12, с. 7].

Нелестную оценку по поводу назначения Н.В. Чарыкова послом в Турции дает С.Ю. Витте. В частности, он писал: «Чарыков человек недурной, порядочный, весьма ограниченный, склонный к занятиям нумизматикой и другими подобными нервоуспокоительными учёными делами, но никак не обладал тою светлостью ума и талантливостью, которая требуется от деятельного дипломата... не ясно почему именно потребовалось взятие из Константинополя такого выдающегося и компетентного человека, как бывший посол Зиновьев, и назначения такого-то во всех отношениях посредственности, как Чарыков» [13, с. 525-526].

Крайности приписываются действиям российского посла в Турции в воспоминаниях писателя А.П. Шполянского. Вспоминая свой путь в эмиграцию, он отмечает, что, по свидетельству бывшего сотрудника посольства, Н.В. Чарыков наводил «панику на Блистательную Порту».

Мемуарист пишет: «Как что, так сейчас приказывает запрячь свою знаменитую четверку серых в яблоках, и мчится прямо к Абдул-Гамиду, без всяких церемоний и протоколов. У султана уже и подбородок трясется, и глаза на лоб вылезают, а Чарыков всё не успокаивается, - пока не подпишешь, не уйду! А не подпишешь, весь твой Ильдыз-Киоск с броненосцев разнесу! Ну, конечно, тот на всё, что угодно, соглашается; Чарыков, торжествуя возвращается в посольство. А через неделюдругую, новый армянский погром, и греческая резня. Но престиж... огромный!» [14, с. 241-242]. Следует отметить, что данные сведения противоречат результатам проведенных исследований о методах работы Н.В. Чарыкова в Турции $[15,16,17,18,19]$. 
Разнообразные свидетельства содержатся в мемуаpax племянника Н.В. Чарыкова - Г.Н. Михайловского. Он высказал мнение, что главным недостатком проектов Чарыкова - Извольского по Проливам было то, что они «игнорировали недружелюбное отношение к вопросу Англии» [20, с. 85]. Применительно к отставке Н.В. Чарыкова с должности посла тот указывает, что прочитал в одной из германских книг, посвящённых Балканам, что Чарыков был уволен за его «боевую славяно- и англофильскую политику, по личному требованию кайзера Вильгельма» [21, с. 25].

Вышеупомянутый С.Ю. Витте отмечает, что Н.В. Чарыков был «уволен от должности константинопольского посла и уволен при особых обстоятельствах; так как обыкновенно послы назначаются членами Государственного совета, а не в Сенат» [13, с. 526].

Таким образом, рассмотренные мемуары можно классифицировать на два основных типа - дневники и воспоминания.

Причем дневники можно разделить так же на два вида - деловые (Ламздорф) и личные (Богданович). Последний вид существенно проигрывает первому в информативности, поскольку в большей степени транслирует сплетни светских салонов, тогда как первый фиксирует факты. Однако личный дневник имеет преимущество перед деловым с точки зрения эмоциональной окрашенности и в определенной степени воспроизводит отношения упоминаемых индивидов.

Важное влияние имеет род деятельности мемуариста. Заметно, что мемуары дипломатов (Соловьев) содержат более взвешенную оценку деятельности Н.В. Чарыкова. Напротив, авторы, не являвшиеся дипломатами (Дон Аминадо), обнаруживают свою некомпетентность, а порой и предвзятость.

Рассмотренные мемуары содержат различные, порой противоположные оценки деятельности Н.В. Чарыкова, что в очередной раз позволяет убедиться в их субъективности. Вместе с тем они помогают точнее формировать понимание мотивов его деятельности и отношения к нему окружающих, вносят уточнения в информацию, содержащуюся в документах официального характера - деловой переписке, циркулярах, записках, донесениях.

\section{СПИСОК ЛИТЕРАТУРЫ:}

1. Чернов О.А. Дипломатическая деятельность и исторические взгляды Н.В. Чарыкова. Самара, 2010. 222 с.

2. Чернов О.А. Мемуарное наследие Н.В. Чарыкова // Известия Самарского научного центра РАН. Т. 16. № 3 (2). С. 577-579.

3. Федоров Г.П. Моя служба в Туркестанском крае (1870-1910) // Исторический вестник. 1913. Т. 134. C. 787-893.

4. Чиркин С.В. Двадцать лет службы на Востоке. Записки царского дипломата. М.: Русский путь, 2006. 368 с.

5. Rosen R.R. Forty years of diplomacy. 2 vols. Vol. 1. London and New York: George Allen \& Unwin LTD., 1922. 259 p.

\section{CONTEMPORARIES' MEMOIRS ABOUT N.V. CHARYKOV'S DIPLOMATIC ACTIVITY} (C) 2016

O.A. Chernov, candidate of historal sciences, associate professor of the Chair of Domestic History and Archeology Samara State University of Social Sciences and Education, Samara (Russia)

Abstract. The article focuses on N.V. Charykov, who was an outstanding Russian diplomat who played an important role in Russia's foreign policy. His activity is reflected in many official documents. However, they not fully represent his Самарский научный вестник. 2016. № 1 (14)
6. Богданович А.А. Три последних самодержца. Дневник. М.: Издательство «Новости», 1990. 608 с.

7. Ламздорф В.Н. Дневник. 1894-1896. М.: Международные отношения, 1991. 456 с.

8. Соловьев Ю.Я. Воспоминания дипломата. М.: социарственное социально-экономическое издательство, 1939. 412 с.

9. Шиллинг М.Ф. Дневник (1899) / Публ., [предисл.] и примеч. В.Е. Авдеева, М.В. Сидоровой // Российский Архив. Т. ХIII. М., 2004. С. 331-398.

10. Таубе М.А. «Зарницы». Воспоминания о трагической судьбе предреволюционной России. М.: РОСПЭН, 2007. $272 \mathrm{c}$.

11. Коковцов В.Н. Из моего прошлого. Воспоминания 1903-1919 гг. В 2-х тт. Т. 2. М.: Наука, 1992. 456 с.

12. Сазонов С.Д. Воспоминания. М.: Международные отношения, 1991. 398 с.

13. Витте С.Ю. Воспоминания. М.: Соцэкгиз, 1960. В 3-х тт. Т. 3.723 с.

14. Дон Аминадо. Поезд на третьем пути. М.: Вагриус, 2000. 378 с.

15. Чернов О.А. Русско-турецкие отношения в ранней дипломатической и научной деятельности Н.В. Чарыкова // Личность в истории в эпоху нового и новейшего времени (памяти профессора С.И. Ворошилова). Материалы международной научной конференции. СПб.: Издательский дом C.-Петербургского государственного университета, 2011. С. 322-326.

16. Чернов О.А. Назначение Н.В. Чарыкова послом России в Турции: смена курса // Россия и исламский мир: история и перспективы цивилизационного взаимодействия. Международная научно-практическая конференция, посвященная 120-летию Карима Хакимова. Уфа: Вагант, 2011. С. 240-242.

17. Чернов О.А. Н.В. Чарыков и военно-морская программа Турции накануне Первой мировой войны // Российская государственность: от истоков до современности. Международная научная конференция, присти. Самара: СНЦ РАН, 2012. С. 172-177.

18. Чернов О.А. «Демарш Чарыкова» в мемуарах Н.В. Чарыкова // Самарский научный вестник. Самара, 2014. № 4 (9). С. 139-140.

19. Чернов О.А. Мемуарное наследие Н.В. Чарыкова // Известия Самарского научного центра РАН. Самаpa, 2014. Т. 16. № 3 (2). С. 577-579.

20. Михайловский Г.Н. Записки. Из истории российского внешнеполитического ведомства. 1914-1920. В 2-х кн. Кн. 1. М.: Международные отношения, 1993. $520 \mathrm{c}$.

21. Михайловский Г.Н. Записки. Из истории российского внешнеполитического ведомства. 1914-1920. В 2-х кн. Кн. 2. М.: Международные отношения, 1993. $688 \mathrm{c}$. уроченная к 1150-летию российской государственно- 
interaction with other civil servants of the Russian empire, and, consequently, do not reflect in full the atmosphere in which the diplomat worked. At the same time, autobiographical sources containing a subjective approach by definition are not capable of giving objective characteristic of his activity. We do not consider the memoirs of the diplomat himself, as our objective is to find out his contemporaries's opinion of him.

The considered memoirs can be classified in two basic types - diaries and memoirs. Diaries can be divided into two types - business and personal. The latter are much less informative than the former. A personal diary has an advantage over a business one from the point of view of the emotional colouring and to a certain degree reproduces attitudes of the individuals described. The memoirist's line of activity is important. Diplomats' memoirs contain a better weighed appraisal of the diplomat's activity. The authors, who were not diplomats themselves, display their incompetence. The memoirs contain different, sometimes opposite assessment of the diplomat's activity, that is another proof of their subjectivity. At the same time, they help to better understand the motives of N.V. Charykov's activity and the attitude of the milieu to him.

Keywords: N.V. Tcharykow, V.N. Lamzdorf, S.D. Sazonov, S.Yu. Vitte, V.N. Kokovtsov, G.P. Feodorov, S.V. Chirkin, R.R. Rozen, A.I. Nelidov, A.A. Bogdanovich, P.A. Shuvalov, N.K. Girs, memoirs, Russian foreign policy.

УДК 930

\title{
«ДЕЛО АНТИСОВЕТСКОЙ ТРОЦКИСТСКОЙ ОРГАНИЗАЦИИ»: ИСТОРИОГРАФИЧЕСКИЕ ЗАМЕТКИ
}

\author{
(C) 2016
}

М.Д. Точеный, кандидат исторических наук, доцент кафедры гуманитарных и социальных дисциплин Ульяновский институт гражданской авиации имени главного маршала авиации Б.П. Бугаева, Ульяновск (Россия)

Аннотащия. Начиная с 1956 года историки, правоведы и представители других общественных и гуманитарных наук пытаются разобраться в том, что случилось с населением нашей страны во второй половине 30 -х годов ХХ века. Почему оно, утратив здравый смысл, поверило в сомнительные идеи И.В. Сталина о превращении миллионов советских граждан, свято веривших в идеалы марксизма-ленинизма, во вредителей-диверсантов? Почему оно, в большинстве своем, требовало жесточайшей расправы над предателями, когда советские газеты сообщили о раскрытии гигантского заговора в рядах РККА?

Статья является попыткой оценить основные взгляды на так называемое «Дело военных» («антисоветской троцкистской военной организации), результатом которого стал расстрел выдающихся советских военачальников во главе с М.Н. Тухачевским - И.П. Уборевича, И.Э. Якира, А.И. Корка и тысяч смелых, талантливых и преданных делу социализма советских военнослужащих. Тем самым вооруженным силам нашей страны, ее обороноспособности был нанесен тяжелейший удар, что, по мнению некоторых исследователей, предопределило колоссальные потери Советского Союза, особенно в первые годы гитлеровской агрессии.

Особенно нас интересует следующий аспект «дела военных» - было ли оно сфабриковано, и «Красный маршал» стал его невинной жертвой, или, наоборот, проведено по всей строгости закона и виновные понесли заслуженное наказание?

Автор оценил основные стороны проблемы - как либерально настроенных исследователей, так и апологетов сталинизма.

Ключевые слова: война, СССР, репрессии в РККА, Красная армия, «дело военных», суд, И.В. Сталин, М.Н. Тухачевский, Ф.Ф. Раскольников, преступление, изменники Родины, шпионы, историография.

Поздно вечером 11 июня 1937 года председатель Военной коллегии Верховного суда СССР В.В. Ульрих провозгласил суровый приговор. М.Н. Тухачевский и семеро лучших советских военачальников признавались виновными в государственной измене, контактах с иностранными государствами в контрреволюционных целях, оказании помощи международной буржуазии, шпионаже и других особо тяжких преступлениях. В ту же ночь их расстреляли, лишили наград и воинских званий и конфисковали все принадлежащее им имущество.

Попытаемся оценить исторические результаты короткого следствия, выполненного методами средневековой инквизиции, закрытого и скоротечного судебного заседания, скорее похожего на спектакль, и вынесенного трибуналом жестокого и несправедливого приговора.

В соответствии с основными постулатами уголовного права и процесса - принципами законности, равенства, справедливости и, главное, принципом всестороннего, полного и объективного исследования обстоя- тельств дела (как говорил Августин Аврелий - «да будет выслушана и другая сторона») - дадим слово представителям всех основных точек зрения и попробуем объективно «взвесить» их аргументы.

Как и в случае с вопросами легитимности следствия и правильности вынесенного по его результатам приговора, точки зрения историков и иных исследователей можно разделить на две основные группы.

Представители первой, в основном дотошные, въедливые историки либерального толка, по сути, повторяют слова, написанные невозвращенцем Ф.Ф. Раскольниковым в 1939 г. в открытом письме к И.В. Сталину:

«Накануне войны Вы разрушаете Красную Армию, любовь и гордость страны, оплот ее мощи. Вы обезглавили Красную Армию и Красный Флот. Вы убили самых талантливых полководцев, воспитанных на опыте мировой и гражданской войн, во главе с блестящим маршалом Тухачевским.

Вы истребили героев гражданской войны, которые преобразовали Красную Армию по последнему слову военной техники и сделали ее непобедимой. 